\title{
Our Fans In The North: The Demand for British Rugby League
}

\author{
by \\ J.C.H. Jones, J.A. Schofield and D.E.A. Giles* \\ University of Victoria, Victoria, British Columbia \\ Department Of Economics, PO Box 1700, STN CSC, V8W 2Y2, \\ Canada
}

\begin{abstract}
$\underline{\text { Abstract }}$
This paper reports the results of estimating a single equation model of an attendance function for British Rugby League over the seasons 1982/83 to 1990/91. The data are panel data covering virtually every team which played in the two division league over the nine year time period. Diagnostic tests indicate that the appropriate model is a semi-log random effects model, where the dependent variable is league attendance weighted by population. The major results are as follows: there are significant positive relationships between league attendance and various measure of team success (although the direction of causality is moot), team quality (as proxied by the two divisions) and the economic quality of team location (as proxied by the unemployment rate); but there is no discernible relationship between league attendance and either success in non-league trophy competitions or measures of exceptional player quality.
\end{abstract}

* The authors are Professors of Economics 


\section{Introduction}

In the literature on professional team sport a standard empirical exercise has been to estimate a demand function. Typically, single equation models are estimated using OLS techniques, where attendance is the endogenous variable and the exogenous variables are some combination (depending on data availability) of factors common to all demand studies (price, income, etc.) and specific to team sports (team success, outcome uncertainty). The results are then used to address a variety of behavioural and policy issues which range from, considering whether teams maximize profits, through determining the optimum structure of a league, to assessing the viability of individual teams. ${ }^{1}$

Unfortunately, and almost inevitably given the emergence of better data sets and the advances in econometric testing, few of these studies are free from criticisms of one kind or another and the result is that the whole literature has the feel of a work in progress. For instance, studies using time series data and OLS procedures tend to gloss over the difficulties that arise from the potential lack of stationarity in the data and so risk introducing spurious regression problems into the estimates. This, in turn, means that the empirical results may be seriously flawed, rendering the behavioral and policy inferences highly suspect.

Consider, for example, the case of British Rugby League. On the one hand, Burkitt and Cameron (1992) use OLS procedures to estimate an attendance function from time series data (1966-1990), but fail to test for stationarity. From their results they deduce that team success is a positive determinant of attendance, and the 1973 restructuring of the league into two divisions could be considered a modest success in promoting both league and team viability. On the other hand, Davies, Downward and Jackson (1995), correcting for the lack of stationarity in their own data and using a VAR model to estimate another attendance function, 
come to opposite conclusions: attendance drives team success; there is no evidence that the league restructuring scheme was a success; and the best way of ensuring league survival is to, "develop the grassroots of the game via the amateur network" (p.1007).

Since the econometrics of the study by Davies et al. are more sophisticated than those employed by Burkitt and Cameron there is a temptation to accept the former results at face value. Yet, the Davies et al. study raises three areas of concern. First, the data base is quite limited, comprising a panel of only five teams which have existed continuously in the First Division from 1964 to 1993 . These teams cover a fraction of the thirty plus teams operating in any one season during this period and, hence, questions arise about the representativeness of the sample. Second, the model courts serious misspecification confined as it is to, basically, one endogenous (attendance) and one exogenous (team success) variable. Third, there is a surprising lack of reported diagnostic testing, given that the criticisms of Burkitt and Cameron by Davies et al. are principally econometric in nature. It is important, therefore, to address these three areas of concern before accepting Davies et al.'s conclusions, and by inference rejecting those of Burkitt and Cameron.

Accordingly, the object of this paper is to reconsider the demand for rugby league by estimating an attendance function for the seasons 1982/83 to 1990/91 inclusive. Our research methodology is to estimate a single equation, multi-variable model using panel data covering virtually every team that played in the first and second division over this time period; and to subject the model to extensive diagnostic testing. From the analytical point of view the time period has the advantage of being one of relative structural stability in the league: two divisions operated throughout and the number of new team entries and exits was at an absolute minimum. This contrasts with the post-1991 era when the number of divisions jumped from 
two to three then back to two, a Super League was introduced and the season shifted from Fall and Winter to Summer.

Our major conclusions are as follows. First, the most appropriate model for analyzing variations in league attendance in this time period is a random effects model in which the dependent variable is attendance weighted by market population (attendance per capita) rather than the more conventional attendance (unweighted). Second, of the exogenous variables, "team success" is an important determinant of attendance; but the success associated with "trophy" competitions did not translate into increased league attendance. Third, "team quality" (as proxied by first and second divisions teams) and economic "market quality" (proxied by the unemployment rate) are also significant determinants of attendance. Finally, all of these conclusions depend crucially on a series of diagnostic tests on which the final form of the estimated model is based. Without them, it is fair to say that the statistical results would be questionable and the associated inferences defective.

The remainder of the paper details the rationale for these conclusions: section II outlines the model; section III considers the empirical analysis; and section IV offers extended conclusions.

\section{The Model}

The regression model underlying our analysis is a variation on a fairly standard approach to estimating the demand for team sport using annual time series data. Our intention is to estimate a single equation model using panel data where team attendance is determined by a series of exogenous variables representing team success and player, team and locational quality. The most critical factor governing the model's empirical content is data availability and the complete model is summarized by equation (1). 
(1) $\mathrm{ATT}=\alpha_{0}+\alpha_{1} \mathrm{LPS}+\alpha_{2} \mathrm{LPP}+\alpha_{3} \mathrm{PZS}+\alpha_{4} \mathrm{PZP}+\alpha_{5} \mathrm{RZS}+\alpha_{6} \mathrm{RZP}+$

$\alpha{ }_{7} \mathrm{CCWS}+\alpha_{8} \mathrm{CCWP}+\alpha_{9} \mathrm{CCFS}+\alpha_{10} \mathrm{CCFP}+\alpha_{11} \mathrm{CCSS}+\alpha_{12} \mathrm{YCWS}$

$+\alpha_{13} \mathrm{YCWP}+\alpha_{14} \mathrm{YCFS}+\alpha_{15} \mathrm{YCFP}+\alpha_{16} \mathrm{LCWS}+\alpha_{17} \mathrm{LCWP}$ $+\alpha_{18} \mathrm{LCFS}+\alpha_{19} \mathrm{LCFP}+\alpha_{20} \mathrm{RTWS}+\alpha_{21} \mathrm{RTWP}+\alpha_{22} \mathrm{RTFS}+$

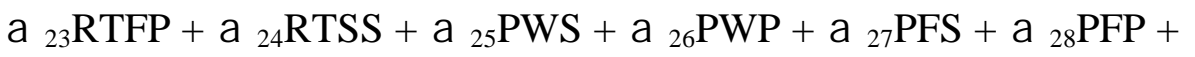

$\alpha_{29} \mathrm{PQS}+\alpha_{30} \mathrm{MAN}+\alpha_{31} \mathrm{BEST}+\alpha_{32} \mathrm{DD}+\alpha_{33} \mathrm{POP}+\alpha_{34} \mathrm{UEM}+$

$\alpha_{35} \mathrm{RAIN}+\alpha_{36} \mathrm{TEMP}+\varepsilon$.

The dependent variable, ATT, is average league attendance by game (total league attendance per season divided by the number of home games) by team. The independent variables can be broadly grouped into measures of: team success, either in the current or preceding season in either league ( $\alpha_{1}$ to $\alpha_{6}$ ) or "trophy" ( $\alpha_{7}$ to $\left.\alpha_{29}\right)$ play; superior player quality ( $\alpha_{30}$ and $\alpha_{31}$ ); the difference in overall team quality between first and second divisions $\left(\alpha_{32}\right)$; and the quality of specific team locations $\left(\alpha_{33}\right.$ to $\left.\alpha_{36}\right)$. The error term is denoted as $\varepsilon$. More precise definitions of the variables, their construction and the basic data sources appear in Table 1 and the footnote below. ${ }^{2}$

On a priori grounds we anticipate the following relationships. The standard expectation is that ATT will be positively related to team success in league competition in both current and previous seasons $\left(\alpha_{1}, \alpha_{2}>0\right)$. Nevertheless, if the results reported by Davies $e t$ al. (1995) are indicative, causation runs from attendance to success. The argument, presumably, is that large crowds produce more revenue which can be spent on better players which, in turn, leads to increased team success.

The coefficients of the promotion zone dummies should be unequivocally positive $\left(\alpha_{3}\right.$, $\alpha_{4}>0$ ), because these variables represent successful involvement in a more meaningful

\section{Table 1}

\section{Variable Definitions}

ATT = average attendance per league game

LPS = league performance of same year, percentage of maximum league points the same year. 
LPP = league performance of previous year, percentage of maximum league points the previous year

PZS = promotion zone dummy of 1 ( 0 otherwise), if the team was in the "promotion zone" (i.e. top 6 ranked teams prior to 1985; top 4 ranked teams 1986-87; top 5 ranked teams post 1986-87) of the second division in the same year.

PZP = promotion zone dummy of 1 ( 0 otherwise), if the team was in the "promotion zone" the previous year.

RZS = relegation zone dummy of 1 ( 0 otherwise), if the team was in the "relegation zone" (i.e. bottom 6 ranked teams except for 1985-86; bottom 5 ranked teams post 1985/86 of the first division in the same year.

RZP = relegation zone dummy of 1 ( 0 otherwise), if the team was in the relegation zone the previous year.

CCWS = Challenge Cup dummy of $1(0$ otherwise $)$ if the team was a winner in the same year.

CCWP = Challenge Cup dummy of 1 ( 0 otherwise) if the team was a winner the previous year.

CCFS = Challenge Cup dummy of 1 ( 0 otherwise) if the team was a finalist the same year.

CCFP = Challenge Cup dummy of 1 ( 0 otherwise) if the team was a finalist the previous year.

CCSS = Challenge Cup dummy of 1 (o otherwise) if the team was a semi-finalist the same year.

YCWS $=$ Yorks Cup dummy of 1 (0 otherwise) if the team is a winner in the same year.

YCWP $=$ Yorks Cup dummy of 1 ( 0 otherwise) if the team is a winner in the previous year.

YCFS = Yorks Cup dummy of 1 ( 0 otherwise) if the team was a finalist the same year.

YCFP = Yorks Cup dummy of 1 ( 0 otherwise) if the team was a finalist the previous year.

LCWS $=$ Lancs Cup dummy of 1 ( 0 otherwise) if the team is a winner in the same year.

LCWP $=$ Lancs Cup dummy of 1 ( 0 otherwise) if the team is a winner in the previous year.

LCFS = Lancs Cup dummy of 1 (0 otherwise) if the team was a finalist the same year.

LCFP = Lancs Cup dummy of 1 ( 0 otherwise) if the team was a finalist the previous year.

RTWS = Regal Trophy dummy of 1 ( 0 otherwise) if the team is a winner in the same year.

RTWP = Regal Trophy dummy of 1 ( 0 otherwise) if the team is a winner in the previous year.

RTFS = Regal Trophy dummy of 1 ( 0 otherwise) if the team was a finalist the same year.

RTFP = Regal Trophy dummy of 1 ( 0 otherwise) if the team was a finalist the previous year.

RTSS = Regal Trophy dummy of 1 (0 otherwise) if the team was a semi-finalist the same year.

PWS = Premiership dummy of 1 ( 0 otherwise) if the team was a winner in the same year.

PWP = Premiership dummy of 1 ( 0 otherwise) if the team was a winner in the previous year.

PFS = Premiership dummy of 1 ( 0 otherwise) if the team was a finalist the same year.

PFP = Premiership dummy of 1 (0 otherwise) if the team was a finalist the previous year.

PQS = Premiership dummy of 1 (o otherwise) if the team was a quarter finalist the same year.

MAN = superstar dummy of 1 ( 0 otherwise) if winner of the Man of Steel award is a member of the team.

BEST = superstar dummy of 1 (0 otherwise) if winner of the Best Division Player (for each division) is a member of the team.

DD = division dummy of 1 (0 otherwise) if the team plays in the first division.

POP = population (mean), two year average (000).

UEM = unemployment rate.

TEMP = average yearly temperature (c), Sept through March.

RAIN = average yearly rainfall $(\mathrm{mm})$, Sept through March.

"contest within a contest" where the outcome is even more uncertain. By the same token, the

relegation zone dummies should also be positive $\left(\alpha_{5}, \alpha_{6}>0\right)$, since this is a contest, replete

with its own attendant uncertainties, to see who stays in the first-division. Of course, the 
reverse could be true: exceptionally poor league performance could be rewarded by reduced attendance despite the increased uncertainty over the outcome.

As far as the "trophy" competitions are concerned we anticipate that success in these contests will have a positive impact on league attendance $\left(\alpha_{7}\right.$ to $\left.\alpha_{29}>0\right)$. In effect, success in cup competition acts as a positive externality for attendance at league games. However, whether some competitions - the Challenge Cup, Yorkshire Cup, Lancashire Cup, Regal Trophy, Premiership - are more important than others in this regard, is moot. Likewise, if there are positive externalities from trophy competitions, are they confined to finalists or are there positive impacts for semi-finalists or quarter-finalists? These propositions can be tested by reference to the individual coefficients and also by a series of joint tests for groups of coefficients.

With regard to player, team and market quality, we expect a positive relationship between attendance and all measures of quality. As crowds are often drawn to see "superstars" (presumably the apogee of player quality) irrespective of the performance of the team, we anticipate that MAN and BEST will be positive $\left(\alpha_{30}, \alpha_{31}>0\right)$. In addition, as the quality of team play is likely to be higher in the first division, the divisional dummy variable (DD) should be positive $\left(\alpha_{32}>0\right)$. We also expect the better quality market areas to be positively associated with attendance. If we proxy "better quality" markets by size (population, POP) and economic condition (proxied by unemployment, UEM) we expect POP to be positive $\left(\alpha_{33}>0\right)$ and UEM to be negative $\left(\alpha_{34}<0\right)$. Lastly, inured as spectators in the north are to bad weather in the Fall and Winter, we, nevertheless, expect that bad weather, as measured by rain and temperature (RAIN, TEMP), will negatively (positively) effect attendance $\left(\alpha_{35}<0 ; \alpha_{36}>0\right)$. 
Finally, we should note again that, in common with most statistical work, the content of the basic estimating equation is determined principally by data availability. In the present context, some variables which should be included in equation (1) on a priori grounds - ticket prices, income and competitive entertainments (sporting and otherwise) are the obvious examples - are omitted because the data are simply unavailable. The data that are available for variables in equation (1) cover almost every team playing in the first and second divisions over the period 1982/83 to 1990/91 (for a listing see Appendix Table A1 below). There is a maximum of 37 and a minimum of 32 teams for any one season, giving a maximum of 309 actual observations in the sample. However, by applying the Ryan-Giles (1998) procedure we were able to fill in the missing gaps and increase the sample size. Thus, the stationarity and functional form testing (III (i) and (ii) below), are undertaken with a larger 333 observation sample using the SHAZAM computer package; but the panel estimations (III (iii), and (iv) below) are undertaken with a 309 observation sample using the TSP package, because the panel is "unbalanced," in the sense that not every time-series observation is available for every cross-section data point.

Given the content of equation (1) we now turn to the empirical analysis.

\section{Empirical Analysis}

The empirical analysis of the model in equation (1) proceeds in the following sequential steps: (i), the data are tested for stationarity; (ii), the specification of equation (1) is tested for functional form and the most appropriate form is selected; and (iii), the interactive effects of the panel data are tested via a series of regression models of (ii) representing the between, fixed, and random effects of the data, and the most appropriate form of the basic model is 
selected; and (iv) in light of the model selected in (iii), the a priori expectations developed in I are considered.

\section{(i) Non-Stationarity Testing}

Table 2 shows the results of the non-stationarity tests for the non-dummy variables in equation (1) using the panel sample of 333 observations. Given the panel nature of the data, the usual single-series unit root tests, such as those of Dickey and Fuller (1981), are not applicable. Various alternative tests have been suggested for this situation (for example,

Table 2

Stationarity Results

\begin{tabular}{|l|c|c|c|}
\hline Variable & No Drift/No Trend & Drift/No Trend & Drift/Trend \\
\hline Attendance & t-ratio & t-ratio $^{*}$ & t-ratio $^{*}$ \\
\hline Population & -1.73 & -45.13 & -43.55 \\
\hline Unemployment & -22.93 & -34.17 & -8.29 \\
\hline $\begin{array}{l}\text { League } \\
\text { Performance } \\
\text { (same year) }\end{array}$ & -6.74 & 2.62 & -10.36 \\
\hline $\begin{array}{l}\text { League } \\
\text { Performance } \\
\text { (previous year) }\end{array}$ & -3.62 & -18.57 & -20.74 \\
\hline Temperature & -2.63 & -18.92 & -22.71 \\
\hline Rain & -2.01 & & -46.29 \\
\hline LAPC & & & -56.27 \\
\hline
\end{tabular}

1. Log of Attendance/Population. See text and Tables 2 and 3 below

* The critical value is -1.645 for a at $5 \%$ one-tail test.

Karlsson and Löthgren, (1999)), and we have used the testing procedure proposed by Wirjanto (1996) to investigate the stationarity properties of our data. Wirjanto's test statistic is asymptotically standard Normally distributed, and as can be seen in Table 2, the null of a unitroot is clearly rejected. Thus, the data need not be adjusted for non-stationarity prior to estimating equation (1). 


\section{(ii) Functional Form}

Table 3 reports some basic diagnostic tests from estimating equation (1) using various functional forms. These are based on OLS estimation with White's (1980) heteroskedasticity consistent covariance matrix as implemented by the SHAZAM computer package. ${ }^{3}$ In comparing models 1 through 4 , model 4 (the semi-log specification) is preferred principally on the grounds that the associated homoskedasticity tests and Ramsey RESET tests are superior to those of models 1 through 3 . Unfortunately, the homoskedasticity tests for model 4 still suggest that the null of homoskedasticity should be rejected, thus compromising this specification for analytical purposes.

In an attempt to rectify this problem we adopted a different definition of the dependent variable in equation (1): attendance per capita (attendance/population, APC) was substituted for the more standard attendance (ATT) used in models 1 through 4. In addition, population (POP) was removed as an exogenous variable. Diagnostic tests from estimating alternative functional forms of this revised model revealed that the semi-log form (LAPC) was preferred. The diagnostic tests of this semi-log form are shown as model 5 in Table 3. The homoskedasticity tests of model 5 confirm, in contrast to model 4 , an absence of heteroskedasticity. Apparently, the non-linear transformation of the dependent variable has smoothed out the error variance. This result, coupled with superior RESET and normality tests, makes model 5 preferred to model 4 on statistical grounds. As these models have different dependent variable variables, their $\bar{R}^{2}$ values cannot be compared.

\section{Table 3}

\section{Diagnostic Tests Of Alternative Specification Of Attendance Functions With Attendance And Attendance Per Capita (APC) As Dependent Variable}




\begin{tabular}{|c|c|c|c|c|c|}
\hline & \multicolumn{5}{|c|}{ Model } \\
\hline $\begin{array}{c}\text { Diagnostic } \\
\text { Tests }\end{array}$ & $\begin{array}{c}\text { Linear } \\
\text { Dependent } \\
\text { Variable } \\
\text { ATT }\end{array}$ & $\begin{array}{c}\text { Log-Log } \\
\text { Dependent } \\
\text { Variable } \\
\text { LATT }\end{array}$ & $\begin{array}{c}\text { Lin-Log } \\
\text { Dependent } \\
\text { Variable } \\
\text { ATT }\end{array}$ & $\begin{array}{l}\text { Semi-Log } \\
\text { (Log-Lin) } \\
\text { Dependent } \\
\text { Variable } \\
\text { LATT }\end{array}$ & $\begin{array}{c}\text { Semi-Log } \\
\text { Dependent } \\
\text { Variable } \\
\text { LAPC }\end{array}$ \\
\hline & (1) & (2) & (3) & (4) & (5) \\
\hline $\bar{R}^{2}$ & 0.8491 & 0.8864 & 0.8402 & 0.8912 & 0.3332 \\
\hline $\begin{array}{l}\text { Jacque Bera } \\
\text { LM Normality } \\
\text { Test } \\
\chi^{2}\end{array}$ & $\begin{array}{c}97.8408 \\
(2 \text { d.f. })\end{array}$ & $\begin{array}{l}4.8335 \\
(2 \text { d.f. })\end{array}$ & $\begin{array}{c}225.3898 \\
(2 \text { d.f. })\end{array}$ & $\begin{array}{l}4.3280 \\
(2 \text { d.f. })\end{array}$ & $\begin{array}{l}\mathbf{3 . 5 2 6 2} \\
(2 \text { d.f. })\end{array}$ \\
\hline \multicolumn{6}{|l|}{$\begin{array}{l}\text { Homoskedasticity } \\
\text { Tests: }\end{array}$} \\
\hline $\mathrm{E}^{* * 2}$ On Yhat & 52.731 (1 d.f.) & 15.241 (1 d.f.) & 39.033 (1 d.f.) & 14.237 (1 d.f.) & $\begin{array}{c}\mathbf{0 . 1 1 2} \\
\text { (1 d.f.) } \\
\end{array}$ \\
\hline $\begin{array}{l}\mathrm{E} * * 2 \text { on } \\
\text { Yhat } * * 2\end{array}$ & $\begin{array}{c}40.556 \\
(1 \text { d..f. }) \\
\end{array}$ & $\begin{array}{c}15.087 \\
(1 \text { d.f. }) \\
\end{array}$ & $\begin{array}{c}27.647 \\
(1 \text { d.f. }) \\
\end{array}$ & $\begin{array}{c}14.270 \\
(1 \text { d.f. }) \\
\end{array}$ & $\begin{array}{c}\mathbf{0 . 0 1 6} \\
\text { (1 d.f.) }\end{array}$ \\
\hline $\begin{array}{l}\mathrm{E}^{* * 2} \text { on } \\
\log \left(\mathrm{Yhat}^{* * 2}\right)\end{array}$ & $\begin{array}{c}32.538 \\
(1 \text { d.f. })\end{array}$ & $\begin{array}{c}15.327 \\
(1 \text { d.f. })\end{array}$ & $\begin{array}{c}24.298 \\
(1 \text { d.f. })\end{array}$ & $\begin{array}{c}14.139 \\
\text { (1 d.f.) }\end{array}$ & $\begin{array}{c}\mathbf{0 . 2 3 0} \\
\text { (1 d.f.) }\end{array}$ \\
\hline $\begin{array}{l}\mathrm{E}^{* * 2} \text { on } \mathrm{X}(\mathrm{B}- \\
\mathrm{P}-\mathrm{G}) \mathrm{Test}\end{array}$ & $\begin{array}{c}117.484 \\
\text { (36 d.f) }\end{array}$ & $\begin{array}{l}35.130 \\
(36 \text { d.f })\end{array}$ & $\begin{array}{l}99.012 \\
(36 \text { d.f) }\end{array}$ & $\begin{array}{l}36.804 \\
(36 \text { d.f })\end{array}$ & $\begin{array}{c}\mathbf{4 3 . 1 5 3} \\
(35 \text { d.f }) \\
\end{array}$ \\
\hline $\begin{array}{l}\log \mathrm{E}^{* * 2} \text { on } \\
\mathrm{X} \text { (Harvey) } \\
\chi^{2}\end{array}$ & $\begin{array}{l}84.849 \\
(36 \text { d.f) }\end{array}$ & $\begin{array}{l}40.401 \\
(36 \text { d.f) }\end{array}$ & $\begin{array}{l}75.982 \\
(36 \text { d.f) }\end{array}$ & $\begin{array}{l}32.638 \\
(36 \text { d.f) }\end{array}$ & $\begin{array}{c}\mathbf{4 3 . 9 0 4} \\
(35 \text { d.f })\end{array}$ \\
\hline $\begin{array}{l}\operatorname{Abs}(\mathrm{E}) \text { on } \mathrm{X} \\
\text { (Glejser) } \chi^{2}\end{array}$ & $\begin{array}{l}161.808 \\
(36 \text { d.f) }\end{array}$ & $\begin{array}{l}44.21 \\
(36 \text { d.f) }\end{array}$ & $\begin{array}{c}146.306 \\
(36 \text { d.f) }\end{array}$ & $\begin{array}{c}43.951 \\
(36 \text { d.f) }\end{array}$ & $\begin{array}{c}\mathbf{4 3 . 4 5 3} \\
(35 \text { d.f })\end{array}$ \\
\hline \multicolumn{6}{|l|}{$\begin{array}{l}\text { RESET Tests } \\
\sim F_{v 1, v 2}\end{array}$} \\
\hline $\begin{array}{l}\text { RESET (2) } \\
(v 1, v 2)\end{array}$ & $\begin{array}{c}131.560 \\
(1,271)\end{array}$ & $\begin{array}{l}2.452 \\
(1,271)\end{array}$ & $\begin{array}{c}120.360 \\
(1,271)\end{array}$ & $\begin{array}{l}0.806 \\
(1,271)\end{array}$ & $\begin{array}{r}\mathbf{0 . 1 8 9} \\
(1,272)\end{array}$ \\
\hline $\begin{array}{l}\text { RESET (3) } \\
(v 1, v 2)\end{array}$ & $\begin{array}{r}69.326 \\
(2,270)\end{array}$ & $\begin{array}{l}11.435 \\
(2,270)\end{array}$ & $\begin{array}{r}69.613 \\
(2,270)\end{array}$ & $\begin{array}{l}0.406 \\
(2,270)\end{array}$ & $\begin{array}{l}\mathbf{0 . 1 4 7} \\
(2,271)\end{array}$ \\
\hline $\begin{array}{l}\text { RESET (4) } \\
(v 1, v 2)\end{array}$ & $\begin{array}{l}46.046 \\
(3,269)\end{array}$ & $\begin{array}{l}1.624 \\
(3,269)\end{array}$ & $\begin{array}{l}46.367 \\
(3,269)\end{array}$ & $\begin{array}{l}0.824 \\
(3,269)\end{array}$ & $\begin{array}{l}\mathbf{0 . 2 9 6} \\
(3,270)\end{array}$ \\
\hline
\end{tabular}

As a further point of comparison, Table 4 shows the complete results of estimating models 4 and 5. The presence of heteroskedasticity in model 4 obviously renders the levels of significance of the individual coefficients, highly suspect. While a direct comparison of the individual coefficients in models 4 and 5 is clearly invidious, it should be noted that there is a great deal of compatibility between their signs and levels of significance. 
To summarize: in statistical terms, model 5, in which the dependent variable ATT is in effect weighted by market size (as measured by population), and population is dropped as an exogenous variable, is the most appropriate form for the study of rugby league attendance in this time period, and, therefore, serves as the basis for all further estimation in this study.

\section{(iii) Panel Estimates}

Taking account of the fact that we have an unbalanced panel of data, Table 5 shows the results of estimating the fixed, random, and between effects versions of model $5 .{ }^{4}$ The Hausman (1978) test indicates that the random effects model cannot be rejected in favour of the fixed effects version and so the former becomes the analytical model of choice. A full range of diagnostic tests, complete with commentary, are shown in Appendix B. Together they establish that the model is well specified statistically.

\section{(iv) Panel Results}

As far as the individual coefficients in Table 5 are concerned the results are mixed. As anticipated, playing success in the same or previous season (LPS and LPP, respectively) is positively and significantly related to attendance. However, the issue of the direction of causality is moot. The fact that LPP is significant and positive suggests some causality from previous success to attendance. However, the significance of LPS in the same model leaves open the possibility of bi-directional causality, but does not formally establish its presence.

\section{Table 4}

\section{Functional Form: Log ATT (LATT) and Log APC (LAPC)}

\begin{tabular}{|l|l|l|l|r|}
\hline & \multicolumn{2}{|c|}{ Model 4 } & \multicolumn{2}{c|}{ Model 5 } \\
\hline & \multicolumn{2}{|c|}{ LATT } & \multicolumn{2}{c|}{ LAPC } \\
\hline Independent Variables & Coefficient & t-ratio & Coefficient & t-ratio \\
\hline
\end{tabular}




\begin{tabular}{|l|c|c|c|c|}
\hline & & & & \\
\hline CONSTANT & 5.6170 & 28.35 & $\mathbf{1 . 8 2 0 6}$ & $\mathbf{2 . 9 3 5}$ \\
\hline LPS & 1.6564 & 9.418 & $\mathbf{1 . 2 8 5 8}$ & $\mathbf{2 . 6 7 6}$ \\
\hline LPP & 0.5318 & 3.177 & $\mathbf{0 . 7 8 7 2}$ & $\mathbf{1 . 7 4 6}$ \\
\hline PZP & -0.0619 & -0.815 & $\mathbf{0 . 0 6 3 9}$ & $\mathbf{0 . 2 8 3}$ \\
\hline PZS & 0.1529 & 1.711 & $\mathbf{0 . 0 8 3 4}$ & $\mathbf{0 . 3 5 9}$ \\
\hline RZS & 0.0762 & 1.006 & $\mathbf{0 . 1 8 9 5}$ & $\mathbf{0 . 7 8 1}$ \\
\hline RZP & 0.3129 & 5.292 & $\mathbf{0 . 5 9 1 6}$ & $\mathbf{3 . 1 3 0}$ \\
\hline CCWS & -0.0882 & -0.678 & $\mathbf{0 . 3 8 4 0}$ & $\mathbf{1 . 0 8 2}$ \\
\hline CCFS & 0.1151 & 0.930 & $\mathbf{0 . 1 4 8 5}$ & $\mathbf{0 . 4 6 2}$ \\
\hline CCWP & -0.2551 & -1.481 & $\mathbf{0 . 2 6 5 3}$ & $\mathbf{0 . 6 6 4}$ \\
\hline CCFP & 0.2798 & 1.890 & $\mathbf{0 . 2 9 9 6}$ & $\mathbf{1 . 0 5 8}$ \\
\hline CCSS & 0.1215 & 1.914 & $\mathbf{- 0 . 0 5 8 9}$ & $\mathbf{- 0 . 3 0 1}$ \\
\hline YCWS & 0.0358 & 0.309 & $\mathbf{- 0 . 6 6 0 5}$ & $\mathbf{- 1 . 1 6 9}$ \\
\hline YCWP & 0.0333 & 0.234 & $\mathbf{- 0 . 6 2 0 7}$ & $\mathbf{- 1 . 2 9 6}$ \\
\hline YCFS & 0.0390 & 0.429 & $\mathbf{0 . 4 1 7 9}$ & $\mathbf{0 . 8 7 3}$ \\
\hline YCFP & 0.0347 & 0.453 & $\mathbf{0 . 3 7 7 3}$ & $\mathbf{0 . 9 5 9}$ \\
\hline LCWS & 0.0829 & 0.641 & $\mathbf{0 . 3 2 5 8}$ & $\mathbf{1 . 1 8 1}$ \\
\hline LCWP & -0.0356 & -0.274 & $\mathbf{0 . 2 5 3 2}$ & $\mathbf{0 . 8 0 5}$ \\
\hline LCFS & 0.0672 & 0.804 & $\mathbf{- 0 . 4 1 1 1}$ & $\mathbf{- 1 . 9 6 4}$ \\
\hline LCFP & 0.0502 & 0.501 & $\mathbf{- 0 . 2 0 0 8}$ & $\mathbf{- 0 . 7 3 7}$ \\
\hline RTWS & -0.0096 & 0.053 & $\mathbf{- 0 . 8 2 6 9}$ & $\mathbf{- 1 . 6 8 1}$ \\
\hline RTWP & 0.0602 & 0.424 & $\mathbf{- 1 . 1 6 7 2}$ & $\mathbf{- 3 . 7 2 4}$ \\
\hline RTFS & 0.1035 & 0.641 & $\mathbf{- 0 . 0 8 7 3}$ & $\mathbf{- 0 . 1 9 3}$ \\
\hline RTFP & 0.1894 & 1.803 & $\mathbf{0 . 4 1 3 1}$ & $\mathbf{1 . 9 7 3}$ \\
\hline RTSS & 0.1040 & 1.739 & $\mathbf{0 . 2 8 9 4}$ & $\mathbf{1 . 4 0 5}$ \\
\hline PWS & -0.0283 & -0.246 & $\mathbf{- 0 . 2 7 3 7}$ & $\mathbf{- 0 . 7 9 8}$ \\
\hline PWP & -0.0958 & -0.870 & $\mathbf{- 0 . 4 5 0 5}$ & $\mathbf{- 1 . 0 6 5}$ \\
\hline PFS & 0.0235 & 0.243 & $\mathbf{0 . 5 3 1 5}$ & $\mathbf{1 . 9 8 3}$ \\
\hline PFP & 0.0304 & 0.469 & $\mathbf{0 . 5 0 1 8}$ & $\mathbf{1 . 5 2 2}$ \\
\hline PQS & -0.0436 & -0.703 & $\mathbf{- 0 . 1 8 7 6}$ & $\mathbf{- 1 . 0 6 2}$ \\
\hline MAN & 0.0259 & 0.203 & $\mathbf{0 . 4 0 3 4}$ & $\mathbf{1 . 0 6 4}$ \\
\hline BEST & -0.1685 & -1.949 & $\mathbf{- 0 . 1 9 4 9}$ & $\mathbf{- 0 . 6 8 8}$ \\
\hline DD & 1.3951 & 18.630 & $\mathbf{0 . 9 2 1 1}$ & $\mathbf{4 . 3 4 5}$ \\
\hline POP & 0.0006 & 4.216 & $/$ & $/$ \\
\hline UEM & -0.0211 & -5.083 & $\mathbf{- 0 . 0 4 4 6}$ & $\mathbf{- 3 . 8 4 0}$ \\
\hline RAIN & 0.0016 & 1.921 & $\mathbf{0 . 0 0 6 8}$ & $\mathbf{2 . 5 6 2}$ \\
\hline TEMP & 0.0375 & 2.060 & $\mathbf{- 0 . 0 3 0 9}$ & $\mathbf{- 0 . 5 4 5}$ \\
\hline & & & & \\
\hline
\end{tabular}

One way around this conjecture would be to use the notions of Granger causality. Regrettably, the number of independent variables in the model combined with the 9-year time period precludes using Granger causality testing in our analysis. Thus in statistical terms, on the basis of our data set, there is no way to conclude definitively whether either Burkitt and Cameron (1992) or Davies et al. (1995) are correct about the direction of causality. 
In addition to success in league play, promotion zone competition in the current season (PZS) has a positive effect on attendance as does relegation zone competition in both the current (RZS) and, in particular, the previous (RZP) season. These results are as expected. The results for the "trophy" competitions, however, are somewhat surprising. Very few of the t-statistics are even greater than 1 and a number of coefficients are anomalously signed. Joint Wald tests for each competition - Challenge, Yorkshire, Lancashire, Regal and Premiership - support a conclusion that such competitions are of relative unimportance for league attendance. All tests (see Table 6) show that the null hypothesis, that trophy competitions do not have a positive impact on league attendance, cannot be rejected. Thus, while trophy competitions are undoubtedly revenue producers for teams there is no evidence that there are any positive external effects on league attendance.

With respect to the quality variables, as hypothesized there is a pronounced difference between first and second division teams and their impact on attendance (DD). The anticipated positive individual superstar effects (MAN and BEST) proxying player quality are not significant and BEST has an incorrect sign. But economic quality as proxied by the unemployment rate (UEM) is clearly very significant. Finally, good weather (high temperature and low rainfall) is a positive determinant of attendance. It should be noted, however, that, although the individual variables (TEMP and RAIN) have the correct signs, they are not particularly statistically significant.

\section{Table 5}

TSP Panel: Dependent Variable Log of Attendance/Population

\begin{tabular}{|l|c|c|c|c|c|c|c|c|}
\hline & \multicolumn{2}{|c|}{$\begin{array}{c}\text { Plain OLS } \\
\text { (Total) }\end{array}$} & \multicolumn{2}{c|}{$\begin{array}{c}\text { Within Effects } \\
\text { (Fixed) }\end{array}$} & \multicolumn{2}{c|}{$\begin{array}{c}\text { Variance Effects } \\
\text { (Random) }\end{array}$} & \multicolumn{2}{c|}{ Between Effects } \\
\hline Variable & Coefficient & t-ratio & Coefficient & t-ratio & Coefficient & t-ratio & $\begin{array}{c}\text { Coefficien } \\
t\end{array}$ & t-ratio \\
\hline & & & & & & & & \\
\hline
\end{tabular}


15

\begin{tabular}{|c|c|c|c|c|c|c|c|c|c|}
\hline Constant & 1.8197 & 3.0784 & & & 1.8675 & 6.0818 & \multirow{2}{*}{\multicolumn{2}{|c|}{6.1254}} & \\
\hline LPS & 1.2996 & 2.5525 & 1.1613 & 6.6869 & 1.1735 & 6.7976 & & & 0.5489 \\
\hline LPP & 0.7848 & 1.6390 & 0.3323 & 2.0793 & 0.3471 & 2.1779 & \multicolumn{2}{|c|}{-6.2546} & -0.4738 \\
\hline$\overline{\mathrm{PZS}}$ & 0.08119 & 0.3325 & 0.1359 & 1.7397 & 0.1364 & 1.7505 & \multicolumn{2}{|c|}{-1.7599} & -0.3232 \\
\hline PZP & 0.07587 & 0.3381 & -0.0205 & -0.2766 & -0.0208 & -0.2816 & \multicolumn{2}{|c|}{0.4926} & 0.0778 \\
\hline RZS & 0.1999 & 0.8034 & 0.1225 & 1.5036 & 0.1240 & 1.5271 & \multicolumn{2}{|c|}{-2.3609} & -0.0427 \\
\hline RZP & 0.5893 & 3.0525 & 0.2131 & 3.2071 & 0.2270 & 3.4339 & \multicolumn{2}{|c|}{9.9805} & 0.7379 \\
\hline CCWS & 0.3933 & 0.7685 & -0.1035 & -0.5833 & -0.0954 & -0.5395 & \multicolumn{2}{|c|}{-65.4028} & -0.1256 \\
\hline CCWP & 0.2458 & 0.4809 & 0.1069 & 0.6989 & 0.1056 & 0.6918 & \multicolumn{2}{|c|}{67.4806} & 0.1419 \\
\hline CCFS & 0.1564 & 0.3419 & -0.1604 & -1.0001 & -0.1556 & -0.9711 & \multicolumn{2}{|c|}{135.510} & 0.1576 \\
\hline CCFP & 0.2916 & 0.7939 & 0.1861 & 1.6130 & 0.1882 & 1.6328 & \multicolumn{2}{|c|}{-116.073} & -0.1745 \\
\hline CCSS & -0.0549 & -0.2073 & 0.0036 & 0.0430 & 0.0037 & 0.0444 & \multicolumn{2}{|c|}{21.4228} & 0.3864 \\
\hline YCWS & -0.6486 & -1.2997 & -0.0125 & -0.0813 & -0.0231 & -0.1502 & \multicolumn{2}{|c|}{61.5251} & 0.1529 \\
\hline YCWP & -0.7105 & -1.4636 & -0.0554 & $\begin{array}{l}-0.3716 \\
\end{array}$ & -0.0646 & -0.4338 & & 000 & 0.0000 \\
\hline YCFS & 0.3935 & 1.0649 & 0.1255 & 1.0190 & 0.1328 & 1.0816 & & 447 & -0.0517 \\
\hline YCFP & 0.4962 & 1.3235 & 0.1224 & 0.9565 & 0.1305 & 1.0232 & -24 & 5999 & -0.1306 \\
\hline LCWS & 0.3212 & 0.6215 & 0.2176 & 1.3433 & 0.2158 & 1.3334 & 87. & 996 & 0.3275 \\
\hline LCWP & 0.2049 & 0.3858 & 0.0964 & 0.5792 & 0.0993 & 0.5973 & -48 & 1601 & -0.2008 \\
\hline LCFS & -0.4018 & -1.0964 & -0.0529 & -0.4265 & -0.0582 & -0.4709 & -25 & 323 & -0.8093 \\
\hline LCFP & -0.1454 & -0.3676 & -0.0488 & -0.3835 & -0.0513 & -0.4040 & & 000 & 0.0000 \\
\hline RTWS & -0.8041 & -1.4068 & -0.0986 & -0.5167 & -0.1098 & -0.5772 & 89. & & 0.2309 \\
\hline RTWP & -1.1622 & 2.1497 & -0.0977 & -0.5231 & -0.1167 & -0.6276 & -13 & 809 & -0.2624 \\
\hline RTFS & -0.0871 & -0.1998 & 0.1289 & 0.93326 & 0.1236 & 0.8948 & -42 & 735 & -0.1973 \\
\hline RTFP & 0.4168 & 1.1889 & 0.1342 & 1.2164 & 0.1383 & 1.2556 & 34. & 250 & 0.1587 \\
\hline RTSS & 0.2769 & 1.0145 & 0.0139 & 0.1578 & 0.0189 & 0.2158 & 10. & 431 & 0.3686 \\
\hline PWS & -0.2873 & -0.7247 & -0.0153 & -0.1239 & -0.0207 & -0.1675 & 41. & 582 & 0.6736 \\
\hline PWP & -0.4101 & -0.9265 & -0.0347 & -0.2395 & -0.0441 & -0.3048 & -53 & 620 & -0.6669 \\
\hline PFS & 0.5389 & 1.7206 & 0.0226 & 0.2219 & 0.0319 & 0.3139 & -14 & 662 & -0.1335 \\
\hline PFP & 0.4874 & 1.5587 & 0.0741 & 0.7305 & 0.0812 & 0.8016 & 27. & 143 & 0.2343 \\
\hline $\mathrm{PQS}$ & -0.1927 & -1.0177 & -0.0582 & -0.9539 & -0.0590 & -0.9689 & & & 0.0983 \\
\hline MAN & 0.4018 & 0.9447 & 0.0259 & 0.1907 & 0.0326 & 0.2412 & 27. & 553 & 0.1463 \\
\hline BEST & -0.2141 & -0.7339 & -0.1026 & -1.0931 & -0.1026 & -1.0940 & & 513 & -0.3629 \\
\hline DD & 0.9078 & 3.9771 & 1.0393 & 9.7089 & 1.0504 & 10.0534 & & 068 & -0.0965 \\
\hline UEM & -0.0448 & -3.6351 & -0.3353 & -5.5841 & -0.0335 & -5.6635 & & 754 & 0.8625 \\
\hline RAIN & 0.0068 & 2.5107 & -0.0009 & -0.7377 & -0.007 & -0.5642 & & & 0.9729 \\
\hline TEMP & -0.0309 & -0.5383 & 0.0406 & 1.7432 & 0.0394 & 1.7057 & & 317 & -0.4584 \\
\hline $\bar{R}^{2}$ & 0.3348 & & 0.434 & & 0.389 & & & & \\
\hline & & & & & $\begin{array}{l}\text { Test of } \\
\text { ffects vs. } \\
\text { effects }\end{array}$ & $\begin{array}{l}\chi^{2}(35 \\
\text { p-value }\end{array}$ & & & $\begin{array}{l}\text { usion: } \\
\text { fixed } \\
\text { for } \\
\text { m effects }\end{array}$ \\
\hline
\end{tabular}

Table 6

Joint Tests For The Significance Of Trophy Competitions

\begin{tabular}{|c|c|c|c|c|}
\hline Trophies & Test & $\begin{array}{c}\text { Wald Result } \chi^{2} \\
(\mathbf{d f})\end{array}$ & $\begin{array}{c}\mathbf{5} \% \text { Critical } \\
\text { Values }\end{array}$ & Conclusion \\
\hline Challenge & CCWS=CCWP=CCFS=CCSS=0 & $\begin{array}{c}1.6633 \\
(4)\end{array}$ & 9.4877 & Cannot reject the null \\
\hline Yorks & YCWS=YCWP=YCFS=YCFP=0 & 3.8467 & 9.4877 & Cannot reject the null \\
\hline
\end{tabular}


16

\begin{tabular}{|c|c|c|c|c|}
\hline Lancs & LCWS=LCWP=LCFS=LCFP=0 & $\begin{array}{c}(4) \\
1.4868 \\
(4)\end{array}$ & 9.4877 & Cannot reject the null \\
\hline Regal & RTWP=RTFS=RTFP=RTSS=0 & $\begin{array}{c}8.8756 \\
(5)\end{array}$ & 11.0705 & Cannot reject the null \\
\hline Premiership & PWS=PWP=PFS=PFP=PQS=0 & $\begin{array}{c}6.0157 \\
(5)\end{array}$ & 11.0705 & Cannot reject the null \\
\hline \multirow{3}{*}{} & $\begin{array}{c}\text { CCWS=CCWP=CCFS=CCSS= } \\
\text { YCWS=YCWP=YCFS=YCFP= } \\
\text { LCWS=LCWP=LCFS=LCFP= } \\
\text { RTWP=RTFS=RTFP=RTSS= } \\
\text { PWS=PWP=PFS=PFP=PQS=0 }\end{array}$ & $\begin{array}{c}19.2033 \\
(22)\end{array}$ & 33.9244 & Cannot reject the null \\
\end{tabular}

\section{(IV) Conclusion}

There are three conclusions which emerge from the foregoing analysis. The first is a fairly obvious technical point but, in light of the methods employed in the literature, bears emphasizing: in single equation models of the demand for team sports using panel data, an appropriate choice of estimator and use of diagnostic testing are critical. This applies to considerations of stationarity, model specification and functional form. Without such testing the data used in estimating the model and the model itself may be inappropriate and, hence, all of the inferences are questionable.

Thus, Davies et al.'s criticism of Burkitt and Cameron's failure to test for stationarity is well taken, although we would argue that the Davies et al. model is misspecified and needs more rigorous testing. Similarly, before adopting particular functional forms and model specifications, an array of appropriate diagnostic tests is required. For example, as Table 3 and 4 indicate, comparing models 4 and 5 on the basis of the size of the $\bar{R}^{2}$ and t-statistics - a fairly standard practice - would result in selecting a specification (model 4) which fails the tests for homoskedasticity. In fact, the $\bar{R}^{2}$ values should not be compared, and the t-statistics are distorted by heteroskedasticity. This, in turn, renders its high $\bar{R}^{2}$ suspect. 
Second, any empirical study can be improved by more and better quality data. This current study could be improved by data on price, income and a longer time series on all variables. As we have only a nine year panel, we cannot be conclusive about the direction of causation between team success and attendance, because we cannot incorporate Granger causality tests. By the same token, we do not have sufficient data on the requisite variables to treat both attendance and playing success as endogenous variables in a multiple equation demand system.

Our results as they stand are compatible with those of Burkitt and Cameron: playing success is a highly significant determinant of attendance; and promotion and relegation zone dummies are also positively related to attendance. Thus, success determines attendance and, as the two division set-up also increases attendance - without two divisions there would be no promotion and relegation zones - this suggests that the post 1973 restructuring of the league is a success, at least over our time period. However, we cannot reject Davies et al.'s proposition that attendance determines success because our time series does not go back far enough; and preferably, promotion and relegation zone variables should really be compared with a time period in which they did not exist (pre-1973).

Third, while more and better data would be useful, our present study does provide some strong support for a number of standard hypotheses. Team success in its different guises - with the exception of the hypothesized positive external effect of trophy competitions - is a significant determinant of attendance. The quality of team play (first and second divisions) is also positively related to attendance as is the "economic quality" (proxied by the unemployment rate) of the market. Player quality, as measured by BEST and MAN, is not significant. But these may not be particularly good measures with time series data, and 
"superstar" effects may be more apparent with cross section (game by game) data. Finally, bad weather, as anticipated, has a negative impact on attendance.

Clearly, to resolve all of the issues raised by Burkitt and Cameron on the one hand, and Davies et al. on the other hand, more and better data are necessary. Until then this study is also part of a literature in progress. 


\section{Endnotes}

We wish to thank Betty J. J. Johnson for exceptional research assistance and Josie Schofield for assistance with data collection.

Since we began this project a number of colleagues have raised the issue of whether three Canadian academics should be analyzing British Rugby League. This is an apparent extrapolation of the view, popular in literary and humanist circles in Canada, that one group should not write about the behaviour of another group, because they rarely get it right or, even when they do, "voice" is being (mis) appropriated. As none of us has played British Rugby League, we are sensitive to the criticisms that we may be unable to get it right or that we have usurped the prerogatives of some more appropriate research group. Our response is twofold.

First, all co-authors were born in the U.K., played rugby (albeit "union" rather than "league") and have watched it extensively over the years. We therefore understand and empathize with the game. More specifically, one co-author was born outside Leeds, remembers the legendary Lewis Jones performing feats of magic on the rugby league field, still follows the results from afar and watches the game whenever in the "North." Another coauthor was born in Wales, developed an early antipathy to "league" ("Y Cynghrair byth, yr Undeb am byth"), but remembers Lewis Jones' magic before he (some would say 'traitorously') "went North." The other co-author was born in Sheffield, and is now a New Zealander who naturally has an encyclopedic knowledge of all things rugby.

Second, we embrace the "Nicol" proposition. Eric Nicol, winner of a Canadian Governor General's literary award, was criticized for writing about professional hockey because "he never played." His reply, which we endorse, was that, in the last analysis, "you don't need to have a baby in order to be a gynecologist" (The Joy of Hockey, p.160). 
${ }^{1}$ The sports demand literature has been surveyed in Cairns et al. (1986) and Cairns (1990). Not all studies estimate OLS single equation models (for examples of multiple equation demand systems in sport see, Jones and Ferguson (1988), Stewart, Ferguson and Jones (1992) and Cocco and Jones (1997)), although it is more common than not; and the data used ranges over single and multi seasons (game by game observations and one observation by team by season, respectively). More recent examples of demand studies for British sports include: soccer (Dobson and Goddard (1992), and Baimbridge, Cameron and Dawson (1996)); cricket (Hynds and Smith (1994)); and rugby league (Burkitt and Cameron (1992), Davies, Downward and Jackson (1995), and Baimbridge, Cameron and Dawson (1995)). There is no study of rugby union. This undoubtedly reflects the amateurish (deliberately?) reporting of attendance and financial data for this heretofore "amateur" game. Presumably this will change with the professionalization of the game. However, the early evidence from both Welsh and English clubs and their actual and potential insolvencies suggest that, rather than professionalize the players, they should professionalize their accountants.

${ }^{2}$ The data sources and calculations of the variables are as follows: Population (POP) data: POP is interpolated between 1981 and 1991 for each year and each area from, OPCS, Census 1981, Key Statistics for Urban Areas, Table 1, HMSO, 1984; and OPCS, Census 1991, Preliminary Report for England and Wales, Table 4, HMSO, 1991, Municipal Yearbook, Vol. 2, 1991. Unemployment (UEM) data: UEM ratio $1981 *$ regional male + female regional UEM rate, where UEM ratio=(male UEM 1981)/(male+female regional UEM 1981). OPCS Census 1981, Key Statistics for Urban Areas, Table 3, HMSO, 1984 (for Male UEM 1981). CSO, Economic Trends, Annual Supplement 1992, Table 22 (for regional male + female UEM each year). Weather (TEMP and RAIN) data: Met. Office, Monthly Weather Report, Vols. 99-109, 
No. 9-12, 1982-91, HMSO. All other variables are taken directly or calculated from,

Rothman's Rugby League Yearbook, various editions

${ }^{3}$ The basic model selection has been done on the basis of OLS procedures. However, below we take proper account of the panel data and perform associated diagnostic tests (see (iii) and Appendix B).

${ }^{4}$ A wide range of model specifications - all sub-sets of model 5 - was explored. There was, however, little real change from the results reported in Table 5. The results may be obtained from the authors on request. 
Appendix Table A1:

Clubs, Divisions and Number of Observations

\begin{tabular}{|c|c|c|}
\hline Club & First Division & Second Division \\
\hline Barrow & 4 & 5 \\
\hline Bradford N & 9 & 0 \\
\hline Carlisle & 1 & 8 \\
\hline Castleford & 9 & 0 \\
\hline Featherstone R & 8 & 1 \\
\hline Halifax & 6 & 3 \\
\hline Hull & 9 & 0 \\
\hline Hull K.R. & 8 & 1 \\
\hline Leeds & 9 & 0 \\
\hline Leigh & 6 & 3 \\
\hline Oldham & 7 & 2 \\
\hline St. Helens & 9 & 0 \\
\hline Warrington & 9 & 0 \\
\hline Widnes & 9 & 0 \\
\hline Wigan & 9 & 0 \\
\hline Workington $\mathrm{T}$ & 2 & 7 \\
\hline Batley & 0 & 9 \\
\hline $\begin{array}{l}\text { Blackpool } \\
\text { (Trafford from 1989) }\end{array}$ & 0 & 7 \\
\hline Bramley & 0 & 9 \\
\hline Cardiff & 0 & 3 \\
\hline Dewsbury & 1 & 8 \\
\hline Doncaster & 0 & 9 \\
\hline Fulham & 1 & 8 \\
\hline Huddersfield & 0 & 9 \\
\hline Hunslet & 2 & 7 \\
\hline $\begin{array}{l}\text { Huyton (Runcorn } \\
\text { 1984-85) }\end{array}$ & 0 & 9 \\
\hline Keighley & 0 & 9 \\
\hline Rochdale $\mathrm{H}$ & 9 & 0 \\
\hline Salford & 3 & 6 \\
\hline Swinton & 2 & 7 \\
\hline Wakefield T & 5 & 4 \\
\hline Whitehaven & 1 & 8 \\
\hline York (Ryedale) & 1 & 8 \\
\hline $\begin{array}{l}\text { Kent Invicta } \\
\text { (Southend) }\end{array}$ & 0 & 2 \\
\hline $\begin{array}{l}\text { Mansfield } \\
\text { (Nottingham) }\end{array}$ & 0 & 7 \\
\hline Sheffield E & 1 & 6 \\
\hline Chorley & 0 & 3 \\
\hline
\end{tabular}




\section{Appendix B: Diagnostic Tests With Panel Data}

Diagnostic tests for models estimated with panel data are not highly developed, and apart from the Hausman test for fixed versus random effects (see Table 5), the TSP and other packages do not include specification tests. However, by "recovering" the residuals after suitable panel estimation, a range of standard, asymptotically valid, tests can be constructed quite simply. To ensure that no autocorrelation was present in the residuals, we first reestimated the Random Effects model with an appropriate first-order serial correlation correction. (See the AR1 command in the TSP Reference Manual, pp.29-34). The results are shown in Table B1, and the associated residuals were then analyzed for any remaining autocorrelation, for Normality, and for heteroskedasticity.

Diagnostic tests for autocorrelation and Normality appear in Table B2. They were constructed by regressing the Random Effects residuals associated with each team against a constant and then using the DIAGNOS command in the SHAZAM package. Both the Goodness-of-Fit and Jarque-Bera Normality tests are reported, and there is no evidence of non-Normality at any reasonable significance level. Lagrange Multiplier tests for serial independence, against alternatives of simple first-order, simple second-order, and general second-order autocorrelation are also present. The alternative hypotheses in each case allow for either autoregressive or moving average processes in the errors for each team. Using these asymptotically valid tests, there is no reason to reject the null of serially independent errors.

A similar approach was adopted to test for homoskedasticity in the residuals from the original panel data estimation. In this case, residuals were "recovered" for each time-period (season), allowing for the "unbalanced" nature of the panel. The results of applying a range of 
Table B1

First Order Serial Correlation (AR1) Estimation For "Variance Effects" Model

\begin{tabular}{|c|c|c|}
\hline \multirow[b]{2}{*}{ Variable } & \multicolumn{2}{|c|}{$\begin{array}{c}\text { Variance Effects (Random) } \\
\text { AR1 Adjustment }\end{array}$} \\
\hline & Coefficient & t-ratio \\
\hline LPS & 0.9777 & 5.9124 \\
\hline LPP & 0.2462 & 1.6520 \\
\hline PZS & 0.1477 & 2.0664 \\
\hline PZP & -0.0161 & -0.2302 \\
\hline RZS & 0.0753 & 1.0009 \\
\hline $\mathrm{RZP}$ & 0.1818 & 2.8705 \\
\hline CCWS & -0.0153 & -0.0909 \\
\hline CCWP & -0.0532 & -0.3526 \\
\hline CCFS & 0.07507 & 0.5392 \\
\hline CCFP & 0.1109 & 1.0100 \\
\hline CCSS & -0.0069 & -0.0959 \\
\hline YCWS & -0.0349 & -0.2463 \\
\hline YCWP & -0.0268 & -0.1914 \\
\hline YCFS & 0.1148 & 1.0093 \\
\hline YCFP & 0.0933 & 0.7762 \\
\hline LCWS & .01592 & 1.0523 \\
\hline LCWP & 0.0392 & 0.2481 \\
\hline LCFS & -0.0186 & -0.1606 \\
\hline LCFP & -0.0218 & -0.1845 \\
\hline RTWS & -0.0216 & -0.1268 \\
\hline RTWP & -0.0039 & -0.0224 \\
\hline RTFS & 0.0981 & 0.7999 \\
\hline RTFP & 0.0553 & 0.5527 \\
\hline RTSS & -0.0081 & -0.1068 \\
\hline PWS & -0.0123 & -0.1099 \\
\hline PWP & -0.0199 & -01494 \\
\hline PFS & 0.0267 & 0.2840 \\
\hline PFP & 0.0659 & 0.6938 \\
\hline PQS & -0.0468 & -0.8389 \\
\hline MAN & -0.112 & -0.0947 \\
\hline BEST & -0.0961 & -1.2015 \\
\hline $\mathrm{DD}$ & 1.0250 & 9.2804 \\
\hline UEM & -0.0334 & -5.1937 \\
\hline RAIN & -0.0001 & -0.0347 \\
\hline TEMP & 0.0484 & 2.1648 \\
\hline$R^{2}$ & 0.9214 & \\
\hline $\bar{R}^{2}$ & 0.8974 & \\
\hline
\end{tabular}

standard such tests appear in Table B3. The headings "W1", "W2" and "W3" refer to Wald tests against various forms of "dependent variable heteroskedasticity". These tests are 
Table B2

Diagnostic Testing (Team-By-Team) For Normality And Autocorrelation

\begin{tabular}{|c|c|c|c|c|c|}
\hline \multirow[t]{2}{*}{$\underline{\text { Club }}$} & \multirow{2}{*}{$\begin{array}{l}\text { Goodness of } \\
\text { Fit } \chi^{2}(3) \\
\end{array}$} & \multirow{2}{*}{$\frac{\text { J.B. }}{\chi^{2}(2)}$} & \multicolumn{3}{|c|}{ LM Tests } \\
\hline & & & $\begin{array}{l}\text { lag } 1 \\
\chi^{2}(1)\end{array}$ & $\begin{array}{c}\operatorname{lag} 2 \\
\chi^{2}(1)\end{array}$ & $\begin{array}{c}\text { Joint } \\
\text { lags } \\
\chi^{2}(2)\end{array}$ \\
\hline Barrow & 4.323 & 0.778 & 0.498 & 0.791 & 0.559 \\
\hline Bradford N & 1.599 & 0.358 & 0.003 & 0.407 & 0.070 \\
\hline Carlisle & 3.075 & 0.435 & 0.529 & 1.267 & 1.506 \\
\hline Castleford & 1.599 & 0.791 & 0.257 & 1.181 & 1.307 \\
\hline Featherstone R & 1.773 & 0.600 & 1.225 & 1.202 & 2.681 \\
\hline Halifax & 1.773 & 0.836 & 1.744 & 0.367 & 3.158 \\
\hline Hull & 1.773 & 0.322 & 1.683 & 0.771 & 3.211 \\
\hline Hull K.R. & 4.019 & 0.978 & 0.939 & 1.392 & 1.064 \\
\hline Leeds & 6.132 & 2.344 & 0.693 & 1.163 & 1.609 \\
\hline Leigh & 6.807 & 1.477 & 0.153 & 1.551 & 1.431 \\
\hline Oldham & 1.599 & 0.106 & 0.523 & 0.365 & 0.311 \\
\hline St. Helens & 7.608 & 0.119 & 0.183 & 0.516 & 0.296 \\
\hline Warrington & 1.599 & 0.687 & 1.635 & 0.997 & 2.434 \\
\hline Widnes & 0.948 & 0.282 & 0.711 & 0.159 & 0.483 \\
\hline Wigan & 3.552 & 0.200 & 0.502 & 0.656 & 0.666 \\
\hline Workington $\mathrm{T}$ & 1.773 & 0.413 & 0.229 & 0.106 & 0.038 \\
\hline Batley & 5.004 & 0.338 & 1.364 & 0.219 & 1.870 \\
\hline $\begin{array}{l}\text { Blackpool } \\
\text { (Trafford from 1989) }\end{array}$ & 0.544 & 0.703 & 0.336 & 1 & 0.095 \\
\hline Bramley & 6.291 & 4.034 & 0.118 & 0.601 & 0.395 \\
\hline Cardiff & 3.359 & I & 1 & 1 & I \\
\hline Dewsbury & 1.773 & 0.741 & 0.707 & 0.688 & 0.929 \\
\hline Doncaster & 1.599 & 1.041 & 1.908 & 0.263 & 3.701 \\
\hline Fulham & 0.774 & 0.028 & 0.103 & 0.298 & 0.056 \\
\hline Huddersfield & 0.773 & 0.809 & 0.823 & 1.354 & 2.106 \\
\hline Hunslet & 0.774 & 0.284 & 1.818 & 1.009 & 2.581 \\
\hline $\begin{array}{l}\text { Huyton (Runcorn 1984- } \\
85 \text { ) }\end{array}$ & 4.884 & 0.862 & 0.443 & 0.790 & 0.469 \\
\hline Keighley & 4.289 & 0.267 & 1.993 & 1.101 & 5.122 \\
\hline Rochdale $\mathrm{H}$ & 6.838 & 1.155 & 0.571 & 1.585 & 1.995 \\
\hline Salford & 1.773 & 0.878 & 0.678 & 1.289 & 1.389 \\
\hline Swinton & 4.829 & 1.729 & 1.012 & 0.014 & 0.999 \\
\hline Wakefield T & 0.948 & 0.574 & 0.502 & 2.194 & 2.456 \\
\hline Whitehaven & 1.773 & 0.527 & 0.291 & 0.497 & 0.289 \\
\hline York (Ryedale) & 3.552 & 0.150 & 0.202 & 1.443 & 1.858 \\
\hline Kent Invicta (Southend) & 3.144 & I & I & 1 & 1 \\
\hline Mansfield (Nottingham) & 1.605 & 0.314 & 0.517 & l & 0.161 \\
\hline Sheffield E & 2.442 & 0.798 & 0.169 & 1 & 0.027 \\
\hline Chorley & 2.882 & 1 & 1 & 1 & 1 \\
\hline
\end{tabular}


constructed by regressing the squared residuals against the level, square, or logarithm of the square of the "fitted" values associated with these residuals. The square of the slope coefficient "t-ratio" is then asymptotically Chi-Square with one degree of freedom. The headings "LM1", "LM2" and "LM3" refer to the corresponding Lagrange Multiplier tests, the statistics being $\left(\mathrm{NxR}^{2}\right)$, where $\mathrm{N}$ is the sample size and $\mathrm{R}^{2}$ is the coefficient of determination from one of the regressions noted above. These statistics are also asymptotically Chi-Square with one degree of freedom under the null, but their finite sample properties differ from those of the Wald tests. With very few exceptions, these tests suggest that heteroskedasticity is not a problem in our models.

Table B3

Homoskedasticity Tests Year-By -Year (Panel)

\begin{tabular}{|c|c|c|c|c|c|c|c|}
\hline Season & W1 & W2 & W3 & LM1 & LM2 & LM3 & $\mathbf{N}$ \\
\hline $82-83$ & 2.193 & 2.301 & 1.608 & 2.179 & 2.280 & 1.626 & 33 \\
\hline 83-84 & 5.803 & 3.463 & $9.480 *$ & 5.222 & 3.319 & $7.769 *$ & 34 \\
\hline $84-85$ & 6.047 & 4.109 & 5.378 & 5.435 & 3.883 & 4.919 & 36 \\
\hline $85-86$ & 0.885 & 0.531 & 1.362 & 0.916 & 0.555 & 1.387 & 34 \\
\hline 86-87 & 1.946 & 0.789 & 4.713 & 1.949 & 0.817 & 4.364 & 34 \\
\hline $87-88$ & 1.183 & 2.274 & 0.205 & 1.214 & 2.256 & 0.216 & 34 \\
\hline 88-89 & 0.005 & 0.489 & 1.018 & 0.005 & 0.512 & 1.049 & 34 \\
\hline $89-90$ & 0.799 & 0.243 & 1.913 & 0.827 & 0.256 & 1.915 & 35 \\
\hline $90-91$ & 4.731 & 2.443 & $8.703^{*}$ & 4.387 & 2.412 & 7.305* & 35 \\
\hline
\end{tabular}




\section{$\underline{\text { References }}$}

Baimbridge, M., S. Cameron and P. Dawson (1995), "Satellite Broadcasting And Match Attendance: The Case Of Rugby League”, Applied Economics Letters, 2, 343-346.

Baimbridge, M., S. Cameron and P. Dawson (1996), "Satellite Television And The Demand For Football: A Whole New Ball Game", Scottish Journal Of Political Economy, 43, 317-333.

Burkitt B., and S. Cameron (1992), "Impact Of League Restructuring On Team Sport Attendances: The Case Of Rugby League”, Applied Economics, 24, 265-271.

Cairns, J.A. (1990) “The Demand For Professional Team Sports”, British Review Of Economic Issues, 12, 1-20.

Cairns, J.A., N. Jennett and P.J. Sloane (1986), “The Economics of Professional Team Sport: A Survey Of Theory and Evidence", Journal of Economic Studies, 13, 3-80.

Cocco, A. and J.C.H. Jones (1997), “On Going South: The Economics Of Survival And Relocation Of Small Market NHL Franchises In Canada", Applied Economics, 29, 1537-1552.

Davies, B., R. Downward and I. Jackson (1995), “The Demand For Rugby League: Evidence From Causality Tests", Applied Economics, 27, 1003-1007.

Dickey, D. and Fuller, W. (1981) "Likelihood Ratio Statistics For Autoregressive Time Series With A Unit Root”. Econometrica, 49, 1057-1072.

Dobson, S.M. and J.A. Goddard (1992), “The Demand For Standing and Seated Viewing Accommodation In The English Football League", Applied Economics, 24, 11551163.

Hausman, J. S. (1978), “Specification Tests In Econometrics”, Econometrica, 46, 1251-71.

Hynds, M. and J. Smith (1994), “The Demand For Test Match Cricket”, Applied Economics Letters", 1, 103-106.

Jones, J.C.H. and D.G. Ferguson (1988), "Location And Survival In The National Hockey League", Journal Of Industrial Economics, 36, 443-457.

Karlsson, Sune and Löthgren, Mickael (1999), “On The Power And Interpretation Of Panel Unit Root Tests”, Working Paper Series In Economics and Finance, No. 299, Stockholm School Of Economics.

Nicol, E. and D. More (1978), The Joy Of Hockey, Hurtig, Edmonton. 
Ryan, K.F. and D.E.A. Giles (1998), “Testing For Unit Roots In Economic Time Series With Missing Observations", in T. B. Fomby and R.C. Hill (eds.), Advances In Econometrics, Vol. 13, JAI Press, Greenwich, CT, 203-242.

SHAZAM (1993) SHAZAM Econometrics Computer Program, User's Reference Manual Version 7.0, McGraw-Hill, New York.

Stewart, K.G., D.G. Ferguson and J.C.H. Jones (1992), “On Violence In Professional Team Sport As The Endogenous Result Of Profit Maximization”, Atlantic Economic Journal, 20, 55-64.

Time Series Processor (TSP), Version 4.2 (1993), TSP International, Palo Alto, CA.

Wirjanto, T.S. (1996), “The Limiting Distributions Of Unit-Root Tests For Data With CrossSectional And Time-Series Dimensions", Statistics And Probability Letters, 30, 7377. 
May 10, 1999 